\title{
Morfologia, valor nutritivo e anatomia de Brachiaria brizantha sob doses de fósforo e idades de corte
}

\section{Morfology, Nutritional value and anatomy of Brachiaria brizantha under phosphorus doses and cutting ages}

\author{
Andréa Krystina Vinente Guimarães ${ }^{1 *}$, José Cardoso Pinto², Valdemar Faquin², Evaristo Mauro \\ de Castro ${ }^{2}$, Paulo Fernandes Boldrin ${ }^{3}$, Mírian Rabelo de Faria², Julian Vanessa Nascimento \\ Marinho $^{1}$
}

\begin{abstract}
RESUMO
Objetivando avaliar o efeito de doses de fósforo e idades de corte na morfologia e valor nutritivo de folhas de B. brizantha Stapf cv. Marandu e correlacionar características anatômicas com o valor nutritivo, foi conduzido um experimento inteiramente casualizado com 4 repetições, em esquema fatorial $3 \times 5$, sendo 3 idades de corte (28, 56 e 84 dias) e 5 doses de $\mathrm{P}\left(20,200,400,600\right.$ e $\left.800 \mathrm{mg} \cdot \mathrm{dm}^{-3}\right)$. O capim-marandu foi cultivado em vasos de $4 \mathrm{dm}^{3}$. Foram medidas as características morfológicas. E confeccionadas lâminas das folhas e as secções fotomicrografadas foram as áreas do esclerênquima (ESC), da bainha parenquimática dos feixes (BPF), do metaxilema (MET), do floema, das células buliformes, espessura do mesofilo (MES), das epidermes e a distância entre feixes. Determinou-se a produção de MS, e os teores de proteína bruta $(\mathrm{PB})$, fibra em detergente neutro $(\mathrm{FDN})$, fibra em detergente ácido (FDA), lignina, a digestibilidade in vitro da matéria seca (DIVMS). $\mathrm{O}$ aumento nas doses de $\mathrm{P}$ e idades de corte proporcionou aumento na MS e redução na DIVMS e PB. Houve correlações positivas entre o MET e FDA; mesofilo, células buliformes e BPF com a DIVMS e PB; e foram negativas entre floema, MET e ESC e PB.
\end{abstract}

Palavras-chave: Capim-marandu; Bromatologia; Digestibilidade in vitro, Adubação fosfatada

\begin{abstract}
Aiming to evaluate the effect of phosphorus doses and cutting ages on the morphology and nutritive value of Brachiaria brizantha Stapf cv. Marandu and to correlate anatomical characteristics with nutritional value, a completely randomized experiment was conducted with 4 replications, in a 3 x 5 factorial scheme, with 3 cutting ages (28, 56 and 84 days) and 5 doses of $\mathrm{P}\left(20,200,400,600\right.$ and $\left.800 \mathrm{mg} . \mathrm{dm}^{-3}\right)$. Marandu grass was cultivated in $4 \mathrm{dm}^{3}$ pots. Morphological characteristics were measured. Leaf slides were made and the photomicrographed sections were areas of sclerenchyma (ESC), parenchymal sheath of bundles (BPF), metaxylem (MET), phloem, bulliform cells, thickness of mesophyll (MES), epidermis and distance between bundles were measured in leaves. The DM production, crude protein (CP), neutral detergent fiber (NDF), acid detergent fiber (ADF), lignin, in vitro dry matter digestibility (DIVMS) were determined. The increase in P doses and cutting ages provided an increase in DM and a reduction in DIVMS and CP. There were
\end{abstract}

\footnotetext{
${ }^{1}$ Universidade Federal do Oeste do Pará. *E-mail: andreavinente@gmail.com

${ }^{2}$ Universidade Federal de Lavras

${ }^{3}$ Universidade de Rio Verde.
} 
positive correlations between MET and FDA; mesophyll, bulliform cells and BPF with DIVMS and PB; and were negative between phloem, MET and ESC and PB.

Keywords: Marandu-grass; Bromatology; In vitro digestibility, Phosphate fertilization

\section{INTRODUÇÃO}

A ampla utilização da B. brizantha Stapf Webster cv. Marandu deveu-se ao fato da elevada produção de forragem, boa capacidade de rebrota, tolerância à seca e persistência (Meirelles \& Mochiutti 1999).

O fósforo é um macronutriente essencial ao bom estabelecimento de plantas forrageiras, no entanto é um dos mais deficientes em solos brasileiros. De acordo com Corsi e Nussio (1993) o nível crítico externo de fósforo para a forrageira Brachiaria brizantha é $18 \mathrm{mg} . \mathrm{L}^{-1}$ e o interno é de $0,22 \%$ da MS.

Solos de baixa fertilidade limitam o crescimento do sistema radicular e níveis de $\mathrm{P}$ ao redor de $10 \mathrm{mg} . \mathrm{dm}-3$ podem ser considerados críticos, pois o aumento do teor de $\mathrm{P}$ no solo até este nível esteve associado com os maiores incrementos do sistema radicular, perfilhamento e produção de matéria seca de capim-colonião (Panicum maximum Jacq.) (Werner \& Haag 1972, Haag \& Dechen 1993).

Para plantas perenes, como a maioria das forrageiras, verifica-se que teores críticos de $\mathrm{P}$ no solo e na planta diminuem acentuadamente com a idade das plantas (Novais \& Smyth 1999).

A baixa disponibilidade de $\mathrm{P}$ nos solos brasileiros resulta em grande prejuízo à produção das plantas, redução no perfilhamento, atraso no desenvolvimento das gramíneas forrageiras, o que faz com que a pastagem tenha uma cobertura deficiente, abrindo espaços para espécies invasoras (Rossi \& Monteiro 1999).

Por outro lado, a quantidade de adubo aplicado é extremamente importante para as forrageiras tanto do ponto de vista agronômico quanto econômico, uma vez que a aplicação de doses exageradas pode provocar deficiência de outros nutrientes, principalmente o ferro $(\mathrm{Fe})$, zinco $(\mathrm{Zn})$ e cobre $(\mathrm{Cu})$ (Olsen et al. 1977). Daí a necessidade fundamental de se saber combinar as espécies forrageiras mais adequadas com as doses, fontes e formas mais convenientes de se efetuar a adubação fosfatada e a colheita da forrageira, relacionada, sobretudo, à idade de corte. 
O conhecimento dos fatores nutricionais limitantes ao crescimento de gramíneas forrageiras é de grande importância para a formação e manejo de pastagens cultivadas. Em ensaios exploratórios de fertilidade do solo realizados no estado de Rondônia constatou-se que o $\mathrm{P}$ foi o nutriente mais limitante ao crescimento de $\mathrm{B}$. brizantha cv. marandu, reduzindo significativamente seus rendimentos de forragem e quantidades absorvidas de P e nitrogênio (N) (Costa et al. 1988, 1997).

Portanto, o objetivo desta pesquisa foi avaliar o valor nutritivo e as correlações entre as características anatômicas e o valor nutritivo de folhas de B. brizantha cv. Marandu, em função das doses de fósforo e idades de corte, cultivadas em vasos.

\section{MATERIAL E MÉTODOS}

O capim-marandu (B. brizantha) foi cultivado em casa de vegetação do Departamento de Ciência do Solo, Universidade Federal de Lavras, em vasos de $4 \mathrm{dm}^{3}$ contendo Latossolo Vermelho distroférrico, textura argilosa, cujas características químicas do solo foram: $\mathrm{pH}: 5,3$; Ca: $0,3 \mathrm{mg} \cdot \mathrm{dm}^{-3} ; \mathrm{Mg}: 0,1 \mathrm{mg} \cdot \mathrm{dm}^{-3}$; Al: 0,7 mg.dm ${ }^{-3}$; Al+H: 7,0 mg.dm ${ }^{-3}$; P: 1,4 mg.dm ${ }^{-3}$; K: 16 mg.dm ${ }^{-3}$, CTC: 7,4 mg.dm ${ }^{-3}$; Cu: 1,2 mg.dm 3. Zn: 0,3 mg.dm ${ }^{-3}$; Mn:1,7 mg.dm ${ }^{-3}$; Fe: 25,8 mg.dm ${ }^{-3}$; B: 0,1 mg.dm ${ }^{-3}$; S: 9,3 mg.dm ${ }^{-3}$; V: $5,9 \%$; MO: 2,4 dag. $\mathrm{kg}^{-1}$; P-rem: 9,9 mg. $\mathrm{L}^{-1}$.

O cultivo foi realizado no período de agosto a novembro de 2009 , em vasos com capacidade de quatro $\mathrm{dm}^{3}$ de solo, no delineamento inteiramente casualizado, com quatro repetições por tratamento, em esquema fatorial 5 x 3 , sendo cinco doses de $\mathrm{P}(20 ; 200$; 400; 600 e $800 \mathrm{mg} \cdot \mathrm{dm}^{-3}$ de P), na forma PA, e três idades de corte das plantas $(28,56$ e 84 dias após o desbaste).

A acidez do solo foi corrigida com calcário dolomítico para elevar a saturação por bases (V\%) para 60\%, incubando-se o solo por 30 dias com umidade próxima a $60 \%$ do volume total de poros (VTP). Uma adubação básica foi aplicada antes da semeadura e constou de $100 \mathrm{mg}$ de $\mathrm{N} ; 100 \mathrm{mg}$ de $\mathrm{K} ; 40 \mathrm{mg}$ de $\mathrm{S} ; 0,8 \mathrm{mg}$ de $\mathrm{B} ; 1,5 \mathrm{mg}$ de $\mathrm{Cu} ; 3,5 \mathrm{mg}$ de $\mathrm{Mn} ; 5,0 \mathrm{mg}$ de $\mathrm{Zn}$ e 0,15 mg de Mo por $\mathrm{dm}^{3}$ de solo, empregando-se fontes PA. As doses de P foram aplicadas juntamente com a adubação básica. Em seguida, 12 sementes da gramínea foram semeadas nos vasos pertinentes, desbastando-se para cinco plântulas por vaso 10 dias após a emergência. 
Foram aplicadas adubações em cobertura com $200 \mathrm{mg}$ de $\mathrm{N}$ e $200 \mathrm{mg}$ de K por $\mathrm{dm}^{3}$, parceladas em quatro vezes.

Para o estudo morfogênico/morfométrico das plantas foram mensurados, com o auxílio de régua, a altura dos perfilhos; número de perfilhos por vaso e taxa de alongamento foliar. A avaliação da altura e do comprimento de estolões das plantas foi realizada medindo-se o comprimento desde o nível do solo até a lígula da última folha completamente expandida. A taxa de alongamento foliar foi feita dividindo-se o comprimento da lâmina foliar pelo período de avaliação, em dias.

Em cada idade de corte, a parte aérea das plantas foi cortada ao nível do solo e mensurada a produção de matéria verde para estimar, posteriormente, a produção de matéria seca (MS) por vaso. As folhas foram utilizadas nas três idades. Parte do material colhido foi preparado para as análises anatômicas. O restante do material vegetal foi colocado em sacos de papel identificados e levados para estufa de circulação forçada de ar à temperatura de $55-60^{\circ} \mathrm{C}$ até peso constante, para a obtenção da produção da MS.

Foram coletadas folhas completamente expandidas, obedecendo ao padrão utilizado por Silva e Alquini (2003): para lâminas e bainhas foram retiradas amostras da porção mediana da terceira folha, contando a partir da folha bandeira e/ou folha mais jovem completamente expandida, no sentido basípeto; para caules ou colmos foram retiradas amostras da porção mediana do entrenó localizado imediatamente acima da inserção da terceira folha supramencionada. As folhas amostradas foram fixadas em solução de formaldeído, ácido acético e etanol 70\% (JOHANSEN, 1940), por 48 horas e, em seguida, conservadas em etanol $70 \%$.

Os cortes foram clarificados com hipoclorito de sódio a 5\%, por $10 \mathrm{~min}$, reidratados por $10 \mathrm{~min}$, corados com safrablau (solução de safranina e azul de Astra 7,5:2,5) e montados em lâminas com glicerina 50\% (KRAUS; ARDUIN, 1997). Foi utilizado microscópio óptico acoplado a uma câmera digital, com a qual foram realizadas fotografias dos cortes. Estas foram utilizadas para as medições dos parâmetros anatômicos, pelo programa de análise de imagem Image Tool (UTHSCSA, San Antonio, Texas, USA), calibrado com régua microscópica fotografada nos mesmos aumentos das fotografias.

As características anatômicas mensuradas nas folhas foram: as áreas do esclerênquima, da bainha parenquimática dos feixes, do metaxilema, do floema, das células buliformes, espessura do mesofilo, das epidermes e a distância entre feixes. 
Foram realizadas análises bromatológicas das folhas para determinação da matéria seca (MS) (ASSOCIATION OF OFFICIAL ANALYTICAL CHEMISTS AOAC, 1980). O teor de proteína bruta (PB) foi determinado pelo método semi-micro Kjeldahl (AOAC, 1995), fibra em detergente neutro (FDN), fibra em detergente ácido (FDA), conforme metodologias descritas por Soest (1963); lignina conforme Soest e Wine (1968) e os valores de digestibilidade in vitro da matéria seca (DIVMS), conforme metodologia de Tilley e Terry (1963).

Após a tabulação dos dados foi feita a análise de variância e as doses de $\mathrm{P}$ foram submetidas ao estudo de regressão, os modelos foram escolhidos de acordo com a lógica biológica, a probabilidade dos coeficientes angulares e o coeficiente de determinação. As variáveis anatômicas foram submetidas à correlação linear de Pearson com os valores de FDN, FDA, PB, lignina e DIVMS.

\section{RESULTADOS E DISCUSSÃO}

A altura das plantas, o número de plantas por vaso, a taxa de alongamento foliar, a produção de matéria seca total da parte aérea e do colmo, o teor de proteína bruta e a DIVMS apresentaram resposta significativa $(\mathrm{P}<0,01)$ para interação idade $\mathrm{x}$ dose.

Constataram-se aos 28 e 56 dias alturas médias de perfilhos de 27,18 e 43,61 cm; por outro lado, houve elevação quadrática da altura das plantas aos 84 dias em resposta ao aumento das doses de $\mathrm{P}$ (Tabela 1). $\mathrm{O}$ valor da dose de $\mathrm{P}$ que maximizou a altura de perfilhos $\left(84 \mathrm{~cm}\right.$ ) foi $570 \mathrm{mg} . \mathrm{dm}^{-3}$ aos 84 dias.

Observou-se, aos 28 dias, o número médio de perfilhos por vaso de 3,3; por outro lado, aos 56 e 84 dias foram determinadas elevações quadráticas da população de perfilhos em função do aumento das doses de $\mathrm{P}$ (Tabela 1). A dose estimada de $\mathrm{P}$ que maximizou o número de perfilhos $(8,0)$ foi $541 \mathrm{mg}^{-\mathrm{dm}^{-3}}$ aos 56 dias e aos 84 dias, o número máximo estimado de perfilhos correspondeu a 15 com a dose estimada de 582 mg.dm ${ }^{-3}$ de $P$.

Registraram-se aos 28 e 84 dias de idade valores respectivos médios de taxa de alongamento foliar de 0,85 e 0,48 cm/dia e para a idade de 56 dias foi determinada elevação quadrática em função do aumento das doses de P (Tabela 1). A dose estimada de $\mathrm{P}$ que maximizou a taxa de alongamento foliar $(0,73 \mathrm{~cm} / \mathrm{dia})$ foi $430 \mathrm{mg} \cdot \mathrm{dm}^{-3}$ à idade de 56 dias. 
Tabela 1. Altura, número de perfilhos, taxa de alongamento foliar de B. brizantha em função da interação dose de $\mathrm{P}$ x idade de corte.

\begin{tabular}{|c|c|c|c|c|c|c|c|}
\hline \multirow[t]{2}{*}{ Idade } & \multicolumn{5}{|c|}{ Dose de $\mathrm{P}\left(\mathrm{mg} / \mathrm{dm}^{3}\right)$} & \multirow[t]{2}{*}{ Equação de Regressão } & \multirow[t]{2}{*}{$\mathrm{R}^{2}$} \\
\hline & 20 & 200 & 400 & 600 & 800 & & \\
\hline \multicolumn{8}{|c|}{ Altura $(\mathrm{cm})$} \\
\hline 28 & 21,75 & 29,55 & 26,05 & 27,0 & 31,55 & $\hat{y}=27,18$ & \\
\hline 56 & 32,05 & 45,46 & 46,12 & 48,6 & 45,84 & $\hat{y}=43,62$ & \\
\hline 84 & 55,25 & 84,3 & 74,35 & 82,85 & 81,38 & $Y=-0,000079 x^{2}+0,0902 x+58,16$ & 0,7 \\
\hline \multicolumn{8}{|c|}{$\mathrm{N}^{\circ}$ Perfilhos (perfilhos/vaso) } \\
\hline 28 & 2,9 & 3,3 & 3,55 & 3,3 & 3,45 & $\hat{y}=3,3$ & \\
\hline 56 & 3,45 & 7,5 & 8,15 & 7,2 & 7,7 & $Y=-0,000016 x^{2}+0,0173 x+3,7$ & 0,81 \\
\hline 84 & 4,03 & 12,05 & 14,23 & 12,93 & 14,15 & $Y=-0,000032 x^{2}+0,03722 x+4,23$ & 0,88 \\
\hline \multicolumn{8}{|c|}{$\begin{array}{c}\text { Taxa de alongamento foliar } \\
(\mathrm{cm} / \text { perfilhos/vaso) }\end{array}$} \\
\hline 28 & 0,81 & 0,93 & 0,80 & 0,88 & 0,84 & $\hat{y}=0,85$ & \\
\hline 56 & 0,62 & 0,72 & 0,70 & 0,72 & 0,64 & $Y=-0,000001 x^{2}+0,00052 x+0,6159$ & 0,84 \\
\hline 84 & 0,39 & 0,53 & 0,50 & 0,47 & 0,51 & $\hat{y}=0,48$ & \\
\hline
\end{tabular}

Fonte: Guimarães, et. al., (2021, p. 06)

$\mathrm{O}$ aumento nas alturas de perfilhos observados com incrementos nas doses de $\mathrm{P}$ também foram registrados por Belarmino (2005) que avaliou o efeito da adubação fosfatada em quatro gramíneas forrageiras, dentre elas o braquiarão. Pesquisas realizadas com o capim-xaraés (B. brizantha) e a B. decumbens apresentaram respostas positivas de incrementos nas alturas dos perfilhos em função das doses de $\mathrm{P}$ aplicadas, por exemplo, no trabalho de Lopes et al. (2011) verificou-se que a adubação fosfatada de estabelecimento influenciou as alturas de perfilho do capim-xaraés com doses de 25 a $100 \mathrm{~kg} / \mathrm{ha}$ de $\mathrm{P}_{2} \mathrm{O}_{5}$, e a aplicação de níveis de $\mathrm{P}$ no estabelecimento da pastagem de $\mathrm{B}$. decumbens provocou aumento linear na altura dessa gramíneas com doses de $\mathrm{P}$ variando de 50 a $250 \mathrm{~kg} / \mathrm{ha}$ de $\mathrm{P}_{2} \mathrm{O}_{5}$ (Mesquita et al. 2004).

O uso de adubação fosfatada, em geral, tem mostrado resultados favoráveis na melhoria do perfilhamento das plantas forrageiras e no volume de matéria seca do sistema radicular em trabalhos realizados em vasos (Werner \& Haag 1986). Considerando que o fósforo desempenha um papel importante no desenvolvimento do sistema radicular 
(Werner \& Hagg 1986) e no perfilhamento das gramíneas (Lira et al. 1994), a sua deficiência reduz a taxa de crescimento inicial e o estabelecimento das forrageiras, além de limitar sua capacidade produtiva e conseqüentemente das pastagens.

Os incrementos no número de perfilhos obtidos neste trabalho corroboram o que foi observado por Cecato et al. (2000), que observaram efeito positivo do fósforo para o número de perfilhos vivos, com incremento do mesmo. Também, Silva (1996), estudando os efeitos da adubação fosfatada na produção de B. decumbens e B. brizantha, destacou que o incremento das doses de $\mathrm{P}$ resultou em aumento no número de perfilhos das gramíneas avaliadas. De acordo com Lopes et al. (2011), a adubação fosfatada teve efeito marcante sobre o perfilhamento inicial do capim-xaraés (B. brizantha) com maior número de perfilhos obtido no intervalo entre 25 e $50 \mathrm{~kg} / \mathrm{ha}$ de $\mathrm{P}_{2} \mathrm{O}_{5}$. A maior população de perfilhos na pastagem em função de um suprimento adequado de $\mathrm{P}$ certamente resulta em melhor cobertura do solo e maior quantidade de forragem disponível para os animais.

O aparecimento de folhas, o alongamento de folhas e de colmos e a duração de vida das folhas são as que determinam diretamente o crescimento das plantas forrageiras. O número de folhas vivas por perfilho, o comprimento final das folhas e a densidade populacional de perfilhos são as variáveis estruturais influenciadas diretamente pelas características morfogênicas, e constituem o índice de área foliar de um pasto, cuja importância é central para o crescimento das gramíneas (Lemaire \& Chapman 1996). O aumento na taxa de alongamento das folhas em função das doses de $\mathrm{P}$ obtido neste trabalho demonstra que esta variável é fortemente influenciada pela adubação fosfatada. Esse efeito também foi observado por Lopes et al. (2011) que observaram aumento no comprimento da lâmina foliar de capim-xaraés (B. brizantha) em função das doses de $\mathrm{P}$, neste trabalho o crescimento foi favorecido pela adubação fosfatada até a dose de 200 $\mathrm{kg} / \mathrm{ha}$ de $\mathrm{P}_{2} \mathrm{O}_{5}$.

As produções de matéria seca da parte aérea e do colmo apresentaram aumentos quadráticos nas idades de 56 e 84 dias (Tabela 2). A maior produção de matéria seca da parte aérea aos 56 dias foi $62,84 \mathrm{~g} / \mathrm{vaso}$, na dose $538 \mathrm{mg} / \mathrm{dm}^{3}$ de $\mathrm{P}$ e aos 84 dias foi 112,3, na dose $600 \mathrm{mg} / \mathrm{dm}^{3}$ de $\mathrm{P}$. Quanto à produção de matéria seca do colmo, foram obtidos valores superiores aos 56 dias (24,7 g/vaso), na dose $500 \mathrm{mg} / \mathrm{dm}^{3}$ de P, e aos 84 dias (56,52 g/vaso), na dose $538 \mathrm{mg} / \mathrm{dm}^{3}$ de P. A produção média de MS das folhas $(\mathrm{P}<0,01)$ aumentou quadraticamente com o incremento das doses de $\mathrm{P}$, obtendo-se maior massa (31,5 g/vaso), na dose $500 \mathrm{mg} / \mathrm{dm}^{3}$ de P (Gráfico 1). Aumentos lineares de MS de capim- 
Marandu com incremento de doses de $\mathrm{P}$ também foram observados por Ramos et al. (1997).

Gráfico 1. Produção de matéria seca das folhas (PMSF) de capim-Marandu sob doses de

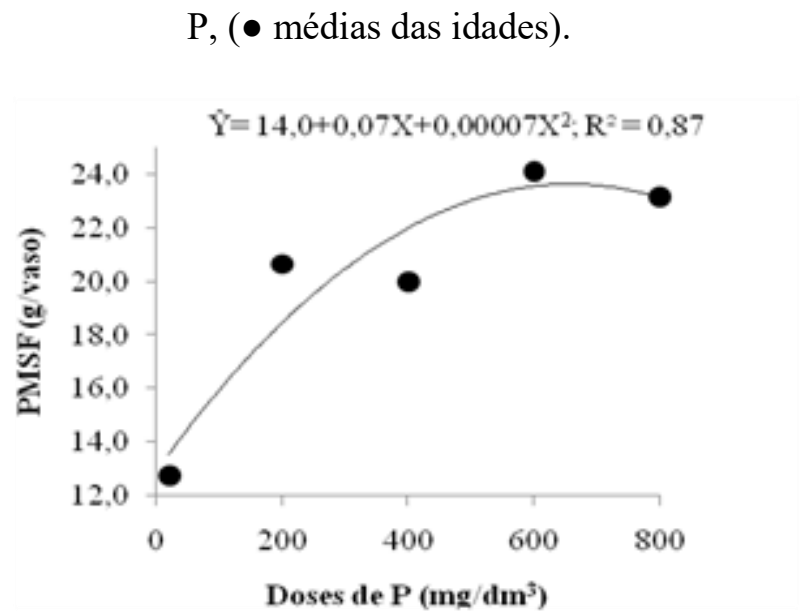

Fonte: Guimarães, et. al., (2021, p. 08)

A produção de MS das folhas ( $\mathrm{P}<0,01)$, a FDN $(\mathrm{P}<0,01)$, a FDA $(\mathrm{P}<0,01)$ e o teor de lignina $(\mathrm{P}<0,05)$ aumentaram com o incremento das idades de corte (Tabela 2). Costa et al. (2007), avaliando intervalos de corte na composição químico-bromatológica de B. brizantha cv. MG-5 observaram acréscimos na massa seca do capim à medida que se aumentou o intervalo de corte de 15 para 60 dias, e diminuição no valor nutritivo com acréscimos nos teores de FDN e FDA que atingiram os valores de 70,82\% e 36\% na MS, respectivamente, e redução no teor de $\mathrm{PB}$ a $8,86 \%$ na MS.

Os valores de DIVMS e de PB reduziram quadraticamente em função das doses de $\mathrm{P}$ aplicadas, em todas as idades de corte avaliadas (Tabela 2). A menor DIVMS, aos 28 dias $(69,3 \%)$, foi obtida na dose $500 \mathrm{mg} / \mathrm{dm} 3$ de $\mathrm{P}$, e aos 56 dias $(53,6 \%)$, ocorreu na dose $250 \mathrm{mg} / \mathrm{dm} 3 \mathrm{de}$ P. Valores inferiores de PB aos 28 (10,54\% na MS), 56 (10,85\% na MS) e 84 dias (6,7\% na MS) ocorreram nas doses 500, 370 e $333 \mathrm{mg} / \mathrm{dm} 3$ de P, respectivamente. O conteúdo de $\mathrm{PB}, \mathrm{FDN}$ e FDA na MS produzida estão de acordo com os valores encontrados por Santos et al. (2008) que relatou na MS de capim-Marandu sob adubação fosfatada aos 28 dias, teores de 6,4\% de PB, 64,6\% FDN e 34,2\% de FDA. De acordo com a Tabela Brasileira de Composição de alimentos para bovinos (VALADARES FILHO et al., 2006) esses valores estão dentro da faixa adequada para a forrageira estudada. Soest (1994) concluiu que 7\% é o teor mínimo de PB para um bom funcionamento da microbiota ruminal. 
Tabela 2. Produções de matérias secas da folha (PMSF), do caule (PMSC), e da parte aérea (PMSPA), teores foliares de fibra em detergente neutro (FDN), fibra em detergente ácido (FDA) e o teor de proteína bruta (PB) e digestibilidade in vitro da matéria seca (DIVMS) das folhas de capim-Marandu sob doses (D) de P e idades de corte (I)

\begin{tabular}{|c|c|c|c|c|c|c|c|}
\hline \multirow[t]{2}{*}{ Idade } & \multicolumn{5}{|c|}{ Dose de $\mathrm{P}\left(\mathrm{mg} / \mathrm{dm}^{3}\right)$} & \multirow[t]{2}{*}{ Equação de Regressão } & \multirow[t]{2}{*}{$\mathrm{R}^{2}$} \\
\hline & 20 & 200 & 400 & 600 & 800 & & \\
\hline \multicolumn{8}{|c|}{ PMSF(g/vaso) } \\
\hline 28 & $3,5 \mathrm{c}$ & $4,7 \mathrm{c}$ & $4,8 \mathrm{c}$ & $4,5 \mathrm{c}$ & $5,0 \mathrm{c}$ & $\hat{y}=4,5$ & \\
\hline 56 & $12,4 \mathrm{~b}$ & $21,9 b$ & $22,4 b$ & $23,9 b$ & $25,7 \mathrm{~b}$ & $\hat{y}=21,26$ & \\
\hline 84 & $22,4 \mathrm{a}$ & $35,3 \mathrm{a}$ & $32,9 a$ & $43,9 \mathrm{a}$ & $38,9 \mathrm{a}$ & $\hat{y}=34,68$ & \\
\hline \multicolumn{8}{|c|}{ PMSC(g/vaso) } \\
\hline 28 & 2,8 & 4,5 & 4,0 & 3,5 & 4,0 & $\hat{\mathrm{y}}=3,76$ & \\
\hline 56 & 22,6 & 47,6 & 49,5 & 48,1 & 50,2 & $Y=-0,00006 x 2+0,06 x+9,7$ & 0,86 \\
\hline 84 & 44,9 & 86,9 & 79,1 & 77,6 & 95,8 & $Y=-0,00013 \times 2+0,14 x+18,8$ & 0,82 \\
\hline \multicolumn{8}{|c|}{ PMSPA(g/vaso) } \\
\hline 28 & 6,3 & 9,3 & 8,8 & 8,0 & 9,0 & $\hat{\mathrm{y}}=8,28$ & \\
\hline 56 & 37,9 & 69,5 & 71,9 & 72,0 & 75,8 & $Y=-0,00013 \times 2+0,14 x+25,2$ & 0,89 \\
\hline 84 & 67,2 & 122,2 & 112,0 & 121,5 & 134,7 & $Y=-0,0002 \times 2+0,24 x+4,03$ & 0,84 \\
\hline \multicolumn{8}{|c|}{ FDN (\% na MS) } \\
\hline 28 & $64,1 b$ & $58,2 \mathrm{~b}$ & $62,4 \mathrm{~b}$ & $62,5 b$ & $63,2 b$ & $\hat{y}=62,08$ & \\
\hline 56 & $59,9 b$ & $67,0 \mathrm{~b}$ & $66,7 b$ & $63,4 b$ & $61,6 b$ & $\hat{y}=63,72$ & \\
\hline 84 & $73,2 \mathrm{a}$ & $68,9 \mathrm{a}$ & $69,4 a$ & $70,2 \mathrm{a}$ & $71,4 \mathrm{a}$ & $\hat{y}=70,62$ & \\
\hline \multicolumn{8}{|c|}{ FDA (\% na MS) } \\
\hline 28 & $24,8 b$ & $25,7 b$ & $26,0 b$ & $25,4 \mathrm{~b}$ & $25,7 b$ & $\hat{y}=25,52$ & \\
\hline 56 & $27,6 \mathrm{a}$ & $26,3 \mathrm{a}$ & $27,2 \mathrm{a}$ & $28,7 \mathrm{a}$ & $28,4 \mathrm{a}$ & $\hat{y}=27,64$ & \\
\hline 84 & $26,9 \mathrm{ab}$ & $26,4 \mathrm{ab}$ & $26,9 \mathrm{ab}$ & $27,7 \mathrm{ab}$ & $27,3 \mathrm{ab}$ & $\hat{y}=27,04$ & \\
\hline \multicolumn{8}{|c|}{ Lignina (\% na MS) } \\
\hline 28 & $4,4 b$ & $4,7 b$ & $4,3 b$ & $5,7 \mathrm{~b}$ & $4,3 b$ & $\hat{y}=4,68$ & \\
\hline 56 & $5,3 \mathrm{a}$ & $5,4 a$ & $5,8 \mathrm{a}$ & $5,7 \mathrm{a}$ & $5,2 \mathrm{a}$ & $\hat{y}=5,48$ & \\
\hline 84 & $5,4 \mathrm{ab}$ & $5,4 \mathrm{ab}$ & $5,8 \mathrm{ab}$ & $5,8 \mathrm{ab}$ & $4,8 \mathrm{ab}$ & $\hat{y}=5,44$ & \\
\hline \multicolumn{8}{|c|}{ Proteína (\% na MS) } \\
\hline 28 & 23,1 & 12,2 & 8,1 & 10,4 & 9,7 & $Y=0,00005 x^{2}-0,05 x+23,04$ & 0,91 \\
\hline
\end{tabular}




\begin{tabular}{cccccccc}
56 & 14,6 & 8,5 & 7,7 & 7,1 & 8,0 & $\mathrm{Y}=0,000027 \mathrm{x}^{2}-0,02 \mathrm{x}+14,56$ & 0,93 \\
84 & 9,9 & 5,7 & 4,7 & 5,7 & 7,4 & $\mathrm{Y}=0,00003 \mathrm{x}^{2}-0,02 \mathrm{x}+10,04$ & 0,9 \\
\hline \multicolumn{7}{c}{ DIVMS (\% na MS) } \\
\hline 28 & 18,07 & 24,17 & 28,71 & 33,21 & 21,7 & $\mathrm{Y}=0,00006 \mathrm{x}^{2}-0,06 \mathrm{x}+84,3$ & 0,84 \\
56 & 44,22 & 41,02 & 49,14 & 42,98 & 36,45 & $\mathrm{Y}=0,00004 \mathrm{x}^{2}-0,02 \mathrm{x}+56,1$ & 0,61 \\
84 & 58,50 & 62,71 & 48,79 & 73,08 & 54,60 & $\hat{y}=40,46$ &
\end{tabular}

Médias seguidas de mesma letra na coluna não diferem entre si pelo teste Tukey $(\mathrm{P}>0,05)$. As equações de regressão são em função das doses de $\mathrm{P}$.

Fonte: Guimarães, et. al., (2021, p. 10)

Considerando os tecidos analisados nas folhas de capim-Marandu houve correlação significativa negativa dos tecidos esclerênquima e metaxilema da nervura central com a DIVMS e a o teor de PB (Tabela 3). Queiroz, Gomide e Maria (2000) quando avaliaram a lâmina foliar de capim-elefante, capim-setária e capim-jaraguá também observaram correlação negativa do esclerênquima com a DIVMS. O esclerênquima produz grande efeito na qualidade da forrageira, em decorrência da grande espessura de sua parede celular (WILSON, 1994).

Os tecidos mesofilo, epiderme abaxial da nervura de menor calibre, BPF e células buliformes apresentaram correlação significativa positiva com a DIVMS e a PB e o mesofilo e a BPF correlacionaram-se negativamente com os teores de FDA, FDN e lignina (Tabela 3). Paciullo et al. (2001) explicam que o mesofilo, por ser composto de células de parede delgada e normalmente não lignificada, apresenta correlação positiva com PB e negativa com os teores de FDA. As células de BPF são consideradas mais resistentes à digestão, pois são passíveis de lignificação, no entanto, no interior dessas células está contido $50 \%$ das reservas de carboidratos e proteínas das folhas. Pode-se inferir que a alta correlação com a DIVMS e a PB ocorreram por que as células estavam pouco lignificadas o que favoreceu o aumento dos teores de PB e DIVMS.

O metaxilema da nervura central correlacionou-se positivamente com o teor de FDA e negativamente com a DIVMS e PB. As células do xilema e fibras associadas apresentam parede espessa e lignificada. As paredes destas células são consideradas indigestíveis nas gramíneas (AKIN, 1989). Esses resultados corroboram os apresentados por Bauer et al. (2008) que verificaram altas correlações positivas de xilema e esclerênquima com FDN, FDA, celulose e lignina e correlações negativas com a DIVMS. 
O floema, metaxilema e esclerênquima da nervura de menor calibre das folhas correlacionaram-se negativamente com os teores de PB. Esses resultados corroboram com os encontrados por Paciullo et al. (2001), pois xilema e esclerênquima apresentaram correlação negativa com os teores protéicos de folhas de capim-braquiária, capim-gordura e tifton 85 .

As altas correlações positivas entre as células buliformes e a DIVMS e PB podem se justificar por que este tipo de célula epidérmica é considerada de alta degradação, pois se assemelha às parenquimáticas, apresentando paredes celulares delgadas e recobertas por uma fina cutícula, com composição química distinta daquela que recobre as demais células epidérmicas (BRITO, 1997).

Tabela 3 Coeficientes de correlações de Pearson dos teores de fibra em detergente ácido (FDA), fibra em detergente neutro (FDN), digestibilidade in vitro da matéria seca (DIVMS), proteína bruta (PB) e LIGNINA com os tecidos mensurados na folha de capim-Marandu sob doses de P e idades de corte

\begin{tabular}{lccccc}
\hline Tecidos & FDA & FDN & DIVMS & PB & LIGNINA \\
\hline ESCNC & 0,12 & $0,31 * * *$ & $-0,29 * *$ & $-0,47^{* * *}$ & $-0,14$ \\
METNC & $0,28^{* *}$ & 0,19 & $-0,39 * * *$ & $-0,31^{* * *}$ & 0,16 \\
EPABNC & 0,09 & 0,02 & $0,30^{* *}$ & 0,14 & $-0,18$ \\
MESOFILO & $-0,22^{*}$ & $-0,36 * * *$ & $0,72^{* * *}$ & $0,52^{* * *}$ & $-0,22 *$ \\
EPABNMC & $-0,08$ & $-0,15$ & $0,49 * * *$ & $0,40^{* *}$ & $-0,13$ \\
BPF & $-0,29 * *$ & $-0,31^{* *}$ & $0,70^{* * *}$ & $0,63 * * *$ & $-0,20$ \\
FLOEMA & 0,08 & 0,17 & $-0,20$ & $-0,35^{* * *}$ & 0,08 \\
METNMC & 0,12 & 0,23 & $-0,22 *$ & $-0,43^{* * *}$ & 0,02 \\
ESCNMC & $-0,02$ & 0,12 & 0,10 & $-0,26 * *$ & 0,01 \\
BUL & $-0,30^{* *}$ & $-0,31^{* *}$ & $0,69 * * *$ & $0,51 * * *$ & $-0,19$ \\
\hline
\end{tabular}

ESCNC (Esclerênquima da Nervura Central), METNC (Metaxilema da Nervura Central), EPABNC (epiderme abaxial da Nervura Central), EPABNMC (epiderme abaxial da nervura de menor calibre), BPF (Bainha parenquimática do Feixe vascular), METNMC (Metaxilema da nervura de menor calibre), ESCNMC (Esclerênquima da nervura de menor calibre), BUL (células buliformes). $* \mathrm{P}<0,1 ; * * \mathrm{P}<0,05 ; * * * \mathrm{P}<0,01$

Fonte: Guimarães, et. al., (2021, p. 11) 


\section{CONCLUSÃO}

Nesta pesquisa, a aplicação de doses crescentes de fósforo até $800 \mathrm{mg} \cdot \mathrm{dm}^{3}$ e o aumento das idades de corte até 84 dias do capim-marandu proporcionaram incrimentos em altura e no número de perfilhos, entretanto ocorreu o espessamento dos tecidos lignificados e dos teores de fibra do capim. Os tecidos mais lignificados correlacionaramse negativamento com os teores de proteína e digestibilidade in vitro, enquanto que as células buliformes se correlacionaram positivamente.

\section{REFERÊNCIAS}

BELARMINO, M. C. J. Superfosfato triplo na produção e qualidade de quatro gramíneas forrageiras tropicais. 2005. 147p. :Il. Tese (Doutorado em Zootecnia). UFLA, Lavras, 2005.

CECATO, U. YANAKA, F. Y.; BRITO, M. R. T.; SANTOS, G. T.; CANTO, M. W.;

ONORATO, W. M.; PETERNELLI, M. Influência da adubação nitrogenada e fosfatada na produção, na rebrota e no perfilhamento do capim-marandu (Brachiaria brizantha [Hochst] Stapf. cv. Marandu). Acta Scientiarum, v.22, n. 3, p.817-822, 2000.

CORSI, M.; NUSSIO, L. G. Manejo do capim elefante: correção e adubação do solo. In: SIMPÓSIO SOBRE MANEJO DE PASTAGEM, 10, 1993, Piracicaba. Anais [...] Piracicaba. 1993. P. 87-116.

COSTA, N. de L.; GONÇALVES, C.A.; OLIVEIRA, J.R. da C. Nutrientes limitantes ao crescimento de Brachiaria humidicola consorciada com leguminosas em Porto Velho-RO. Porto Velho: EMBRAPA-UEPAE Porto Velho, 1988. 4p. (Comunicado Técnico, 70).

COSTA, N. de L.; GONÇALVES, C.A.; RODRIGUES, A.N.A. Nutrientes limitantes ao crescimento de Brachiaria decumbens em Rondônia. In: CONGRESSO BRASILEIRO DE CIÊNCIA DO SOLO, 27. Rio de Janeiro, 1997. Anais[...]Rio de Janeiro: SBCS, 1997. p.328-330. 
HAAG, H. P.; DECHEN, A. R. Deficiências minerais em plantas forrageiras. In: PEIXOTO, A. M.; MOURA, J. C. FARIA, V. P. (Ed.) Pastagens: fundamentos da exploração racional. Piracicaba: FEALQ, 1993. p. 85-110.

LEMAIRE, G.; CHAPMAN, D. Tissue flows in grazed plant communities. In: HODGSON, J.; ILLIUS, A.W. (Eds.) The ecology and management of grazing systems. Wallingford:CAB International, 1996. p.3-36.

LIRA, M.A.; FARIAS, I.; FERNANDES, A.P.M. Estabilidade de resposta do capimbraquiária (Brachiaria decumbens Stapf) sob níveis crescentes de nitrogênio e fósforo. Revista Brasileira de Zootecnia, Viçosa, v. 29, n.7, p.1151-1157, 1994.

LOPES, J.; EVANGELISTA, A. R.; PINTO, J. C.; QUEIROZ, D. S.; MUNIZ, J. A. Doses de fósforo no estabelecimento de capim-xaraés e estilosantes Mineirão em consórcio. Revista Brasileira de Zootecnia, Viçosa, v.40, n.12, p.2658-2665, 2011.

MEIRELLES, P.R.L.; MOCHIUTTI, S. Formação de pastagens com Capim Marandu (Brachiaria brizantha cv. Marandu) nos Cerrados do Amapá. Macapá: Embrapa Amapá, 1999. 3p. (Embrapa Amapá. Recomendações técnicas, 7).

MESQUITA, E.E.; FONSECA, D.M.; PINTO, J.C. et al. Estabelecimento de pastagem consorciada com aplicação de calcário, fósforo e gesso. Ciência e Agrotecnologia, Lavras, v.28, n.2, p.428-436, 2004.

NOVAIS, R. F.; SMYTH, T. J. Fósforo em solos e plantas em condições tropicais. $1^{\text {a }}$. ed. Viçosa: UFV, 1999.

OLSEN, S. R.; BOWMAN, R. A.; WATANABE, S. F. Behaviour of phosphorus in the soil and interactions with other nutrients. Phosphorus in Agriculture, USDA, v. 70, n.1, p. 31-45, 1977.

ROSSI, C.; MONTEIRO, F.A. Doses de fósforo, épocas de coleta e o crescimento e diagnose nutricional nos capins braquiária e colonião. Scientia Agricola, v. 56, p. 1101-1110 (Supl), 1999.

SILVA, J. E. P. Parâmetros produtivos e atividade de fosfatase ácida em três gramíneas forrageiras cultivadas com doses de fósforo. Piracicaba: ESALQ, 1996, 81p. (Dissertação de Mestrado em Zootecnia). 
WERNER, J.C.; HAAG, H.P. Estudos sobre a nutrição mineral de alguns capins tropicais. Boletim de Indústria Animal, v.29, n.1, p.191-245, 1972.

WERNER, J.C., HAGG, H.P. Estudos sobre a Nutrição Mineral de Capins Tropicais. Boletim da Indústria Animal, v.18. 49p. 1986.

Recebido em: 01/06/2021

Aprovado em: 25/06/2021

Publicado em: 30/06/2021 